The final publication is available at Elsevier via http://dx.doi.org/10.1016/j.ijfatigue.2014.01.026 @ 2014. This manuscript version is made available under the CC-BY-NC-ND 4.0 license http://creativecommons.org/licenses/by-nc-nd/4.0/

\author{
Elsevier Editorial System(tm) for International Journal of Fatigue \\ Manuscript Draft
}

Manuscript Number: IJFATIGUE-D-13-00446R1

Title: Fatigue characterization and modeling of AZ31B magnesium alloy spot-welds

Article Type: Original Research Paper

Keywords: characterization; fatigue modeling; magnesium; spot-weld

Corresponding Author: Mr. Seyed Behzad Behravesh, Ph.D.

Corresponding Author's Institution: University of Waterloo

First Author: Seyed Behzad Behravesh, Ph.D.

Order of Authors: Seyed Behzad Behravesh, Ph.D.; Hamid Jahed, Ph.D.; Steve Lambert, Ph.D.

Manuscript Region of Origin: The Americas 
1

\title{
Fatigue characterization and modeling of AZ31B magnesium alloy spot-welds
}

\author{
Seyed Behzad Behravesh*, Hamid Jahed, Steve Lambert \\ Mechanical and Mechatronics Engineering Department, University of Waterloo, Waterloo, Ontario, N2L- \\ 3G1, Canada \\ *Corresponding Author: Tel. +1-519-721-1073; Fax: +1-519-885-5862; \\ Email: sbbehravesh@uwaterloo.ca
}

\begin{abstract}
Cyclic behavior of AZ31B spot-welds was studied using different specimen configurations, and compared with steel and aluminum spot-welds. Fatigue strength of magnesium spot-welds was similar to aluminum and less than steel. Three failure modes were observed in tensile-shear specimens and one mode of failure in cross-tension specimens. Fatigue crack initiation life was 50\% and $30 \%$ of the total life for tensile-shear and cross-tension specimens, respectively. A number of available fatigue models were assessed by predicting fatigue life of magnesium spot-welds. Although these models do not account for the asymmetric cyclic hardening behavior, some of them performed successfully for magnesium spotwelds.
\end{abstract}

Keywords: Magnesium; spot weld; characterization; fatigue modeling

\section{Introduction}

Magnesium (Mg), with the lowest density among engineering metals, has attracted significant attention in the automotive industry. The trend in the average $\mathrm{Mg}$ usage per car has been rapidly increasing from $3 \mathrm{~kg}$ in 2005 to $20 \mathrm{~kg}$ in 2010, and is projected to reach $50 \mathrm{~kg}$ in 2015 [1]. Almost all $\mathrm{Mg}$ 
alloys being used in this industry are in non-structural components, which are mostly in the form of castings $[1,2]$. To achieve its role as a major material, the application of $\mathrm{Mg}$ to load bearing components is necessary. It is therefore essential to examine the merits of components made of $\mathrm{Mg}$ under both static and cyclic loads. Wrought Mg alloys in general have superior mechanical properties compared to cast alloys $[3,4]$. Therefore, wrought alloys are widely investigated as an alternative material for load-bearing automobile parts. AZ31 is the most common wrought $\mathrm{Mg}$ alloy in industry [5], with diverse applications in aerospace, military, automotive, and computer industries [6].

From a joining perspective, resistance spot welding (RSW) is the predominant joining technique in automobile body assembly lines [7]. Owing to the new interest of the automotive industry in $\mathrm{Mg}$, several studies have been performed on the application of RSW process to Mg alloys. These studies can be categorized into two major groups: $\mathrm{Mg}$-to-Mg similar joints and $\mathrm{Mg}$ to other metal (dissimilar) joints. Investigations of Mg-to-Mg RSW similar joints deal with different aspects of weld characterization, e.g., effect of surface condition on RSW strength [8], effect of welding conditions on microstructure and static strength of spot-welds $[9,10]$, and nugget growth simulation [11]. Work on magnesium RSW dissimilar joints have mainly focused on Mg-to-steel and Mg-to-aluminum, as they are the dominant metals in automobile body fabrication [12, 13].

Service reports of automobiles show that a major portion of structural durability issues are related to spot-welds [14], which is due to the fact that spot-welds act as stress concentration sites, and are therefore more susceptible to fatigue failure. As a result, studying the fatigue behavior of spot-welds is of great significance. Published research available regarding fatigue characterization of RSW of $\mathrm{Mg}$ alloys is limited to a very few studies. Behravesh et al. $[15,16]$ investigated the effect of nugget diameter on fatigue resistance of spot-welds, and showed that fatigue resistance within low cycle fatigue (LCF) regime may be enhanced by increasing nugget size; however, this effect diminishes in the high cycle fatigue (HCF) domain [15]. Depending on the cyclic load level, three different failure modes may occur in fatigue testing: interfacial, partially-interfacial and coupon failures [15, 16]. 
Many researchers have focused on developing models to estimate the fatigue life of spot-welds. The main approaches in these models include: fracture mechanics [17], structural stress [18], and local strain [19]. The fracture mechanics approach considers a measure of stress intensity factor (SIF) or J-integral as the fatigue damage parameter, and relates this parameter to the fatigue life or the crack growth rate. The structural stress approach neglects the effect of any stress concentration, and calculates a measure of stress by superposing the effects of different forces and moments at the spot-weld. The structural stress is taken as the factor which controls the fatigue failure. The local strain approach, in contrast to the other two approaches, considers a spot-weld as a blunt notch with a finite radius. A measure of local strain at the spot-weld edge is usually assumed as the damage parameter in this approach.

Available fatigue models for spot-welds have been verified for steel and aluminum with symmetric tension-compression hardening behavior. Due to the asymmetric cyclic behavior of wrought $\mathrm{Mg}$ alloys, applicability of these models must be examined for Mg spot-welds. To the best of authors' knowledge, there is no published work available for fatigue modeling of magnesium spot-welds.

The present research was aimed at characterizing the fatigue behavior of AZ31B and its spot-welds from a macroscopic point of view. Cyclic behavior of AZ31B was examined through fatigue testing. Fatigue strength and modes of failure under cyclic loading were studied on spot-welded specimens in tensile-shear and cross-tension configurations. Different approaches for fatigue modeling of spot-welds were introduced and one fatigue model based on each approach was reviewed and examined for magnesium spot-welds. Investigated fatigue models were correlated with experimental data.

\section{Material and Specimens}

The material investigated in this research was AZ31B-H24 hot-rolled magnesium sheet. The sheets were provided by Magnesium Elektron of North America (MENA) in $2 \mathrm{~mm}$ and $4 \mathrm{~mm}$ thicknesses. The chemical composition and mechanical properties are shown in Table 1 and Table 2, respectively [15]. 
Table 1: Chemical composition of AZ31B-H24 Mg alloy

\begin{tabular}{ccccl}
\hline Element & Al & Zn & Mn & Mg \\
\hline Weight $\%$ & 2.73 & 0.915 & 0.375 & Bal. \\
\hline
\end{tabular}

Table 2: Mechanical properties of AZ31B-H24 Mg alloy

\begin{tabular}{cccc}
\hline Direction & $\begin{array}{c}\mathbf{0 . 2 \%} \text { offset yield } \\
\text { strength }(\mathbf{M P a})\end{array}$ & $\begin{array}{c}\text { Ultimate Tensile Strength } \\
(\mathbf{M P a})\end{array}$ & Elongation (\%) \\
\hline Rolling (RD) & $224(3.5)^{\mathrm{a}}$ & $292(0.6)$ & $14(3.0)$ \\
Transverse (TD) & $281(0.4)$ & $320(0.5)$ & $22(2.6)$ \\
\hline a $\quad$ values in parentheses are standard deviations.
\end{tabular}

Fatigue testing of the base metal was performed on sub-size specimens to prevent buckling during compressive reversals. For the same reason, the specimens were machined from a sheet with $4 \mathrm{~mm}$ thickness. Common geometries for flat specimens, recommended in the ASTM standard [20], are straight throughout the reduced section. Monotonic tensile and especially fatigue testing on standard specimens showed that many of them failed under the extensometer knife edge, or even outside the gage length, due to the uniform stress distribution all along the reduced section. Therefore, the specimen geometry shown in Figure 1, which has a continuous curvature within the reduced section, was adopted in this research for fatigue testing.

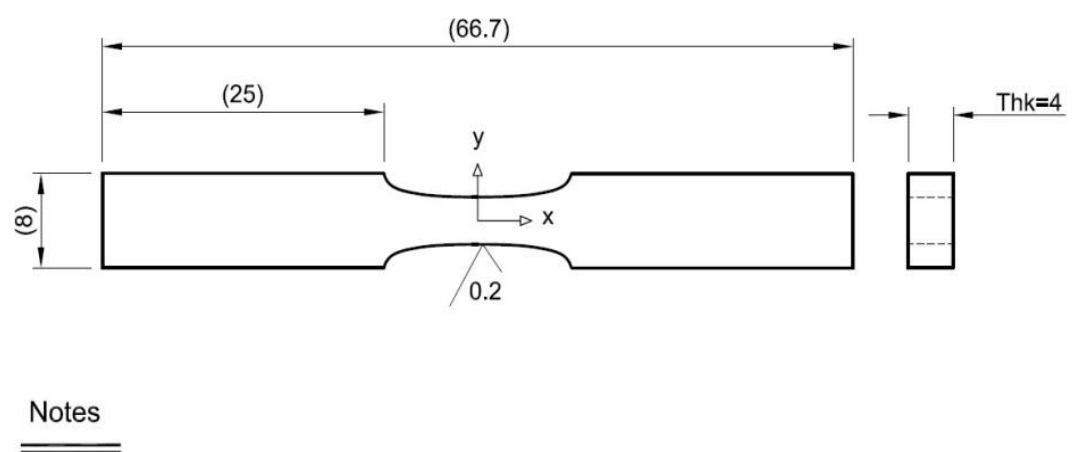

\begin{tabular}{|c|c|}
\hline$x(\mathrm{~mm})$ & $y(\mathbf{m m})$ \\
\hline 0.00 & 2.00 \\
\hline 0.46 & 2.00 \\
\hline 0.91 & 2.00 \\
\hline 1.37 & 2.01 \\
\hline 1.83 & 2.02 \\
\hline 2.28 & 2.03 \\
\hline 2.74 & 2.05 \\
\hline 3.20 & 2.07 \\
\hline 3.67 & 2.10 \\
\hline 4.13 & 2.14 \\
\hline 4.61 & 2.18 \\
\hline 5.09 & 2.25 \\
\hline
\end{tabular}

\begin{tabular}{|c|c|}
\hline$x(\mathbf{m m})$ & $y(\mathbf{m m})$ \\
\hline 5.59 & 2.32 \\
\hline 6.10 & 2.42 \\
\hline 6.62 & 2.54 \\
\hline 7.13 & 2.70 \\
\hline 7.57 & 2.91 \\
\hline 7.85 & 3.14 \\
\hline 8.01 & 3.32 \\
\hline 8.17 & 3.56 \\
\hline 8.35 & 4.00 \\
\hline 33.35 & 4.00 \\
\hline 33.35 & 0.00 \\
\hline & \\
\hline
\end{tabular}

1. All dimensions are in ( $\mathrm{mm}$ ) except the surface roughness which is in micro-meter.

2. Coordinates of points according to a quarter are given in the table.

3. Axes $x$ and $y$ are axes of symmetry.

Two types of spot-welded specimens were investigated in this research: tensile-shear (TS) and crosstension (CT). Two different designs for the TS specimens were employed, as shown in Figure 2. 
(a)

100
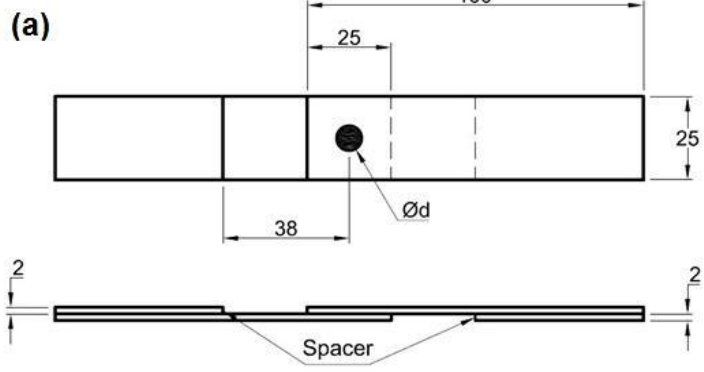

(b)
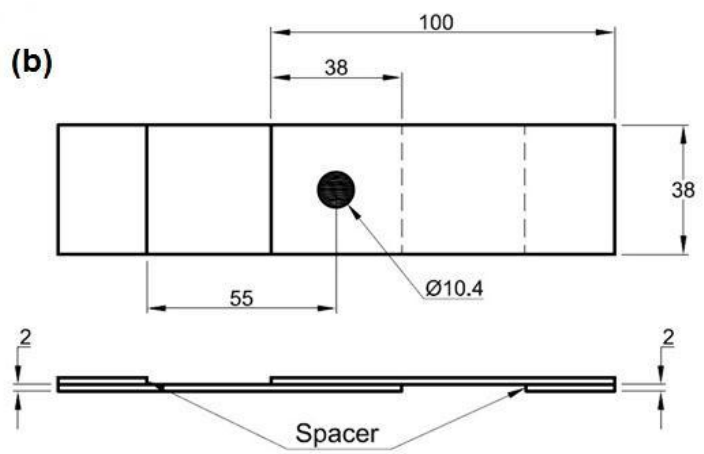

The design of the narrow TS specimen, Figure 2(a), is according to the American Welding Society (AWS) standard [21] and resistance welding manual [22]. The wide TS specimen geometry, Figure 2(b), is more common in the literature. To compensate for the coupons' offset and prevent initial bending of the specimens, two spacers with the same thickness as the coupons were attached to the ends of the TS specimens. Figure 3 illustrates the design of the CT specimens, which is in accordance with the resistance spot welding manual [22].

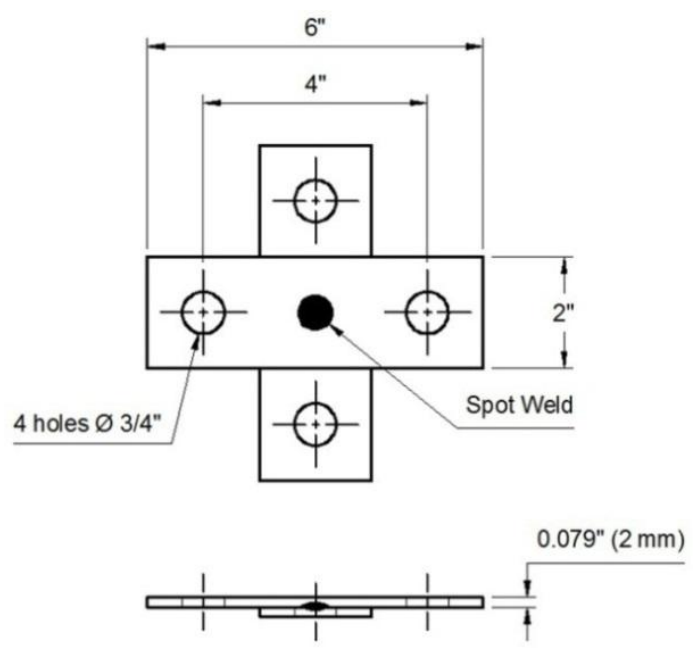

Five sets of spot-welded specimens in TS and CT configurations were prepared with an AC spotwelding machine. Different welding parameters were used to achieve different spot-weld nugget 
diameters. Table 3 summarizes the specifications of the specimens and the coding. Nugget sizes were measured after monotonic testing as the average diameters of the bonding area, along and perpendicular to the loading direction.

Table 3: Spot-welded specimens coding and process parameters

\begin{tabular}{cccccc}
\hline $\begin{array}{c}\text { Specimen } \\
\text { set }\end{array}$ & Configuration & Welding current (kA) & $\begin{array}{c}\text { Welding time } \\
(\mathbf{c y c l e})\end{array}$ & $\begin{array}{c}\text { Electrode force } \\
(\mathbf{k N})\end{array}$ & $\begin{array}{c}\text { Avg. nugget } \\
\text { diameter }(\mathbf{m m})\end{array}$ \\
\hline A & TS ${ }^{\text {a }}$ & 26 & 10 & 4 & $8.2(0.7)$ \\
C & TS & 30 & 8 & 4 & $9.5(0.1)$ \\
E & TS & 34 & 8 & 4 & $10.4(0.2)$ \\
F & TS-W b & 34 & 8 & 4 & $10.4(0.2)$ \\
G & CT & 34 & 8 & 4 & $10.4(0.2)$ \\
\hline
\end{tabular}

a Standard size tensile-shear, Figure 2(a)

b Wide tensile-shear, Figure 2(b)

c $\quad 1$ cycle $=1 / 60 \mathrm{sec}($ Power frequency $=60 \mathrm{~Hz})$

d values in parentheses are standard deviations.

The work by Behravesh et al. [16] provides a detailed discussion of the effect of process parameter on static and fatigue performance of $\mathrm{Mg}$ spot-welds.

\section{Experimental Work}

\subsection{Testing procedures}

Fatigue testing of the base metal, AZ31B-H24, was conducted on the specimen shown in Figure 1. Engineering strain was measured using an extensometer with $6 \mathrm{~mm}$ gauge length and $\pm 0.8 \mathrm{~mm}$ travel. Fatigue testing was performed in strain-control mode for approximately $10^{4}$ cycles, and then stopped and switched to load-control mode, once the load response had stabilized. The main reason for controlling the load was to increase the frequency. The testing frequency was $0.1-0.15 \mathrm{~Hz}$ and $3-10 \mathrm{~Hz}$ for strain- and load-control testing, respectively. The tests were run in the fully reversed loading condition, i.e., the strain ratio, $\mathrm{R}$, was $-1\left(\mathrm{R}=\mathrm{L}_{\min } / \mathrm{L}_{\max }\right.$, where $\mathrm{L}_{\min }$ and $\mathrm{L}_{\max }$ are minimum and maximum loads, respectively). 
Tests were stopped if the life exceeded $10^{7}$ cycles, and considered run-outs. Another criterion for stopping the test in the strain-control mode was a $50 \%$ load drop.

Fatigue testing of spot-welded specimens was performed on the specimen sets shown in Table 3. Fatigue tests were conducted under load-control with a load ratio $\mathrm{R}=0.2$; except for specimen set $\mathrm{F}$ for which $\mathrm{R}=0.1$. A sinusoidal waveform was applied and the loading frequency was between 2 and $30 \mathrm{~Hz}$ depending on the load level. Final separation of coupons was considered as failure. Tests were stopped after $10^{7}$ cycles and considered run-outs. The load and cross head displacement histories, number of cycles, as well as the failure modes were recorded in all fatigue tests.

\subsection{Results and discussion}

\subsubsection{Base metal}

Figure 4 illustrates the second and half-life hysteresis loops for different strain amplitudes. This figure reveals a number of features of the cyclic behavior of AZ31B-H24.

First, comparing the second and the half-life hysteresis indicates that the material shows some cyclic hardening behavior, in terms of tensile or compressive peak stresses. Narrower hysteresis loops for the stabilized cycle compared with the second cycle confirms this.

Dissimilar peak stresses in tension and compression, even though the strain amplitude is symmetric, is an attribute of AZ31B sheet under cyclic loading. The unusual asymmetric shape of the hysteresis loop is pronounced, especially at higher strain amplitudes, where plasticity prevails.

Another cyclic feature is that in the loading reversal, i.e., from compression to tension, there is a distinct "inflection point" where the slope of the hardening curve starts increasing. Similar to other asymmetric cyclic features, the inflection point is more distinguishable at high strain amplitudes. This inflection point did not appear on the unloading curve in this study, even at the highest strain amplitudes. However, other experimental results for very large strain amplitudes, e.g., 3.5\%, reveal an inflection point on the unloading reversal [23]. 
These observations are attributed to different plastic deformation mechanisms, i.e., twinning and untwinning during in-plane compression and tension reversals, respectively. More detailed explanation of the cyclic behavior of AZ31B sheet can be found in [24, 25].
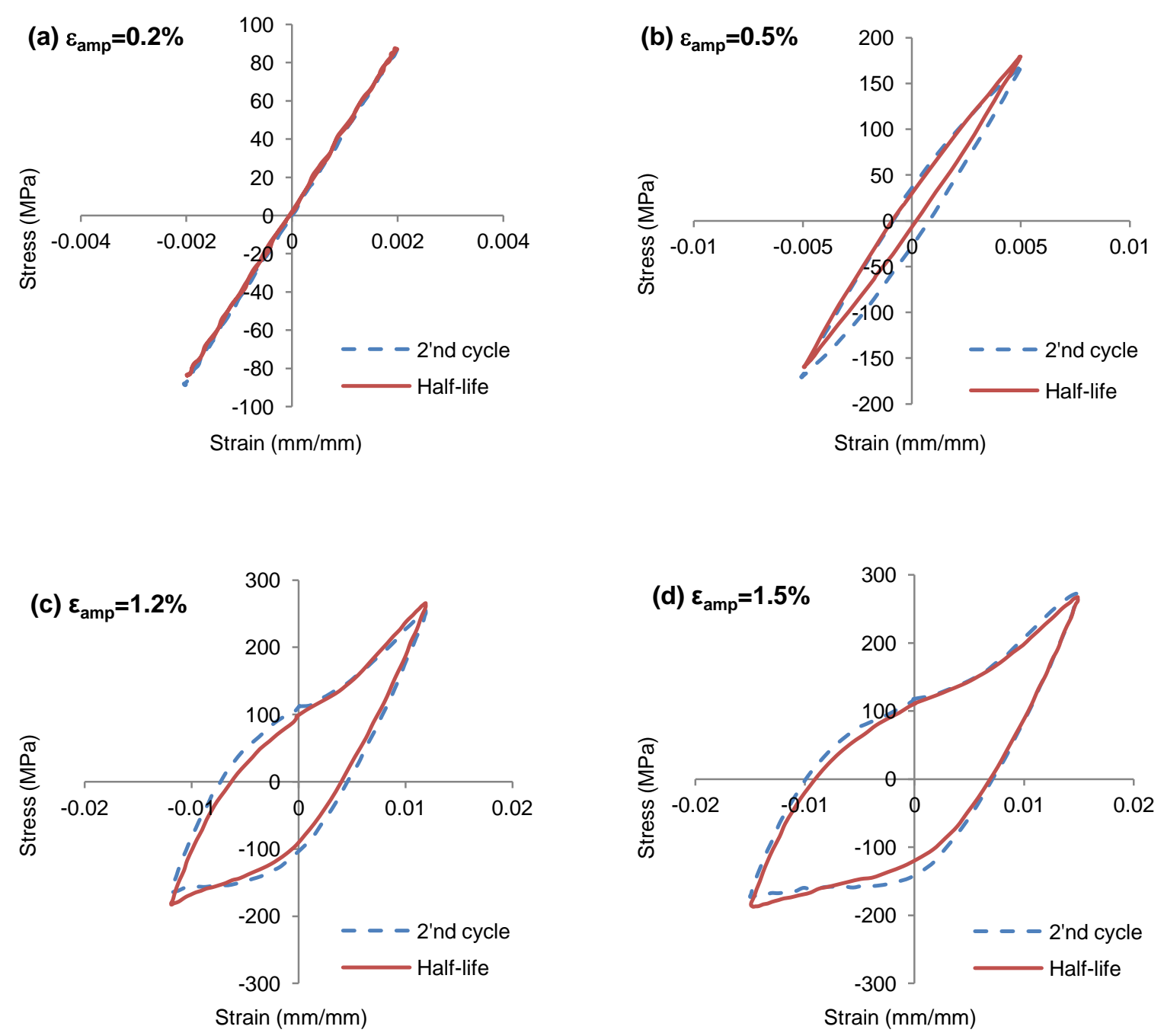

\subsubsection{Spot-welds}

\section{A. Load-life curve}

Fatigue testing of spot-welded specimens resulted in the raw data shown in Figure 5. The load-life curves shown in this figures were obtained from a bi-linear regression fit using a log-log scale. Comparing the load-life curves corresponding to TS specimens, i.e., sets $\mathrm{A}, \mathrm{C}$, and $\mathrm{E}$, reveals that enlarging the nugget size has insignificant effect on fatigue strength (in terms of load range). 


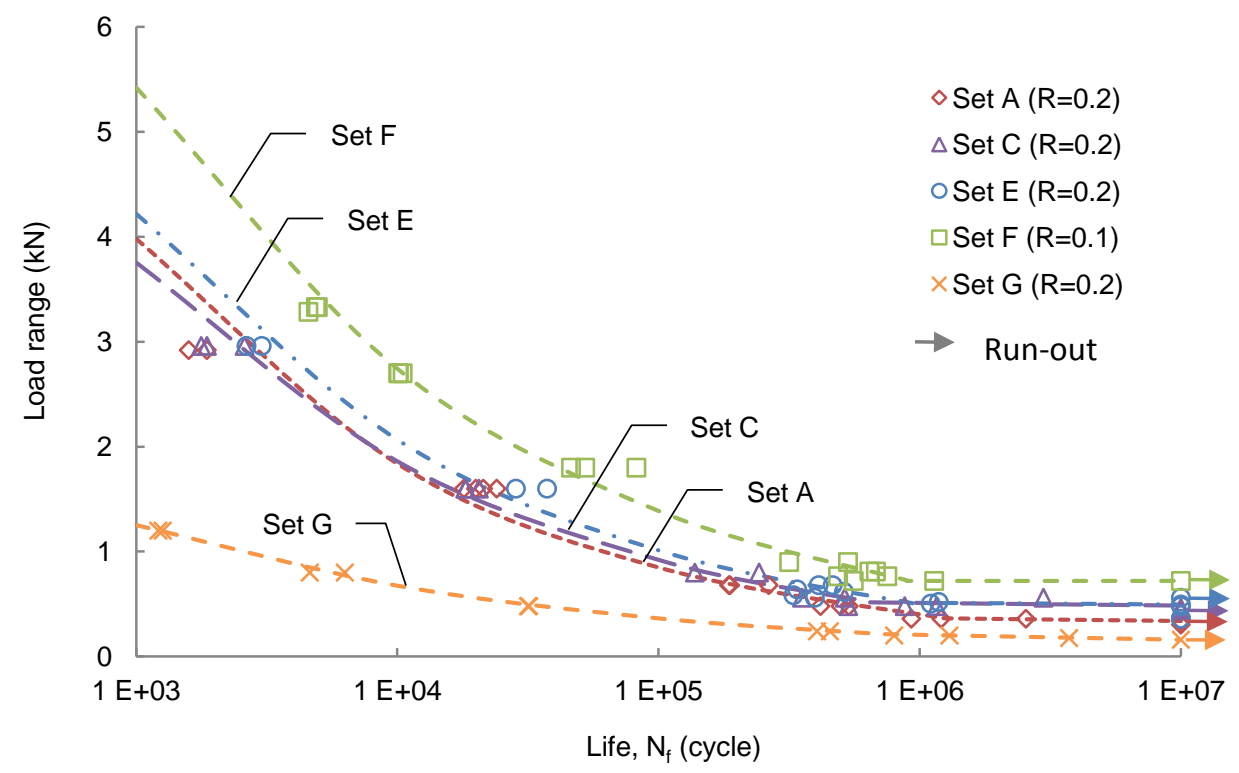

Comparison between specimen sets A-E and set $\mathrm{F}$ indicates that increasing the coupon width and decreasing the mean load improve the fatigue strength for LCF, and this effect gradually diminishes for HCF. Fatigue test results on CT specimens, i.e., set G, show a significant drop in fatigue strength as compared to TS specimens with the same nugget size, i.e., sets E and F. This observation demonstrates that cyclic loading normal to spot-welds is more destructive than shear dominated loading. The endurance limit is $0.34 \mathrm{kN}, 0.44 \mathrm{kN}, 0.48 \mathrm{kN}, 0.72 \mathrm{kN}$, and $0.16 \mathrm{kN}$ for specimen sets $\mathrm{A}, \mathrm{C}, \mathrm{E}, \mathrm{F}$, and $\mathrm{G}$, respectively. Similar effects have been reported for steel [26] and aluminum [27]. However, a recent study reported that increasing the nugget size resulted in decreasing the fatigue strength of spot-welds in AISI304 stainless steel [28].

Figure 6 shows a comparison of fatigue strengths (in terms of load range) for magnesium, aluminum $[29,30]$, and steel $[31,32]$ spot-welds in the TS configuration. 

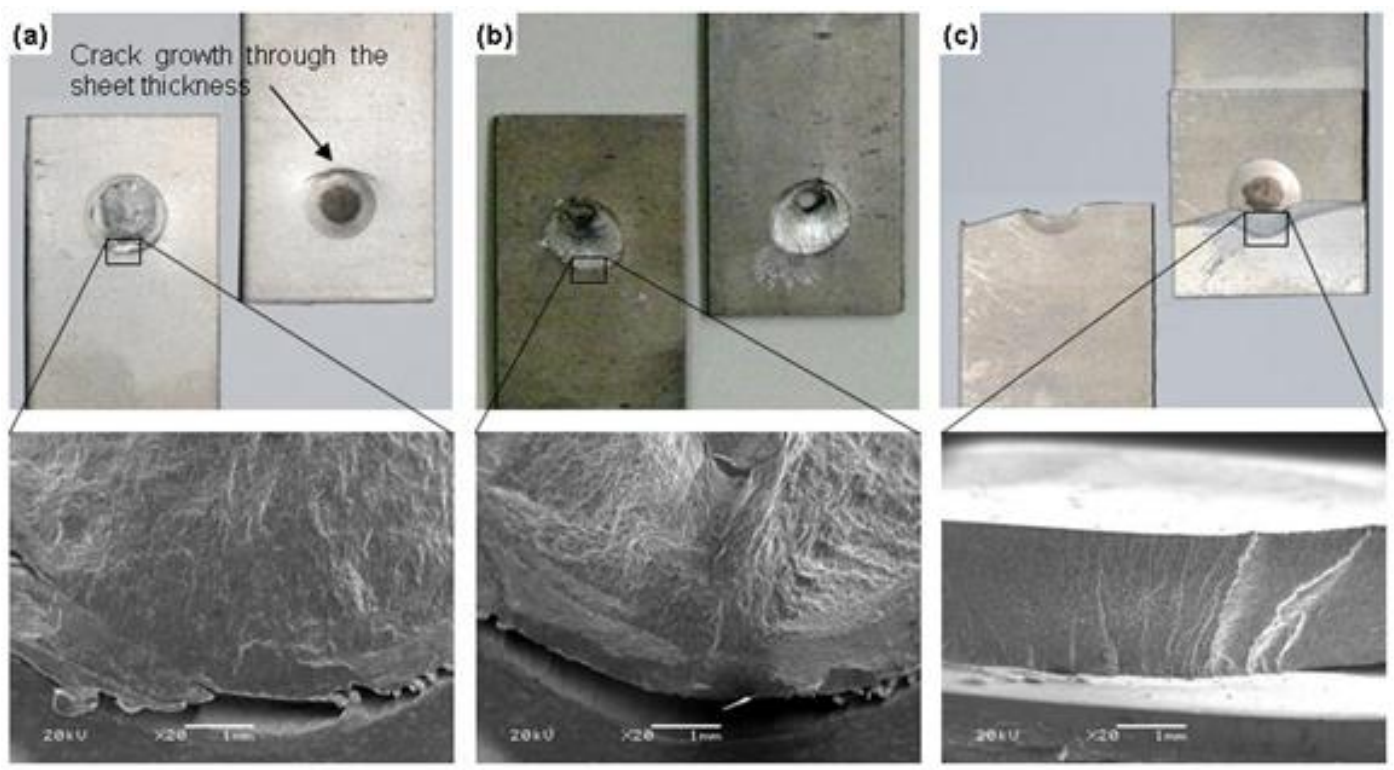

In the interfacial failure mode, Figure 7(a), a crack initiated from the nugget edge in the load-bearing side of the nugget. The crack then propagated through the nugget until complete separation of coupons, while the crack also grew through the coupon thickness. Therefore, the fatigue strength in this mode of failure mainly depends on the size and strength of the nugget. This failure mode was observed only when a very high cyclic load was applied.

Coupon failure, shown in Figure 7(c), is the most common mode of failure in TS specimens. In this failure mode, a crack started either from the base metal or from the interface of the base metal and HAZ, depending on the load level. The crack then propagated through the coupon thickness and extended perpendicular to the loading direction, until the coupons were separated. Fatigue life is therefore independent of nugget strength, but rather depends on cyclic loading level and dimensional parameters, such as coupon width and sheet thickness. Coupon failure was observed at lower loads, in the intermediate and HCF regimes.

Partially-interfacial failure rarely occurred under cyclic loading as a transition between interfacial and coupon failures. Cracks in this mode, as shown in Figure 7(b), nucleated from the same location as for interfacial failure, and grew first inside the nugget and then through the sheet thickness, following the bonding area. It can be seen that, similar to interfacial failure, there was another crack in this mode through the thickness, which was not as critical as the main crack. This mode of failure was observed in a 
narrow region between very low and low cycle regimes, i.e., when fatigue life was between $3 \times 10^{3}$ and $10^{4}$ cycles.

The CT spot-welded specimens failed only in button-pullout mode, as shown in Figure 8. The fatigue crack in this failure mode started from the nugget edge, on the gripping sides of one coupon, and propagated through the sheet thickness, following the FZ and around the nugget. The spot-weld nugget was left on one coupon and a hole on the other after the coupons were separated. The specimens that failed within the LCF regime exhibited button-pullout failure in both coupons, Figure 8(a). However, the CT specimens in HCF failed in button-pullout mode, Figure 8(b).
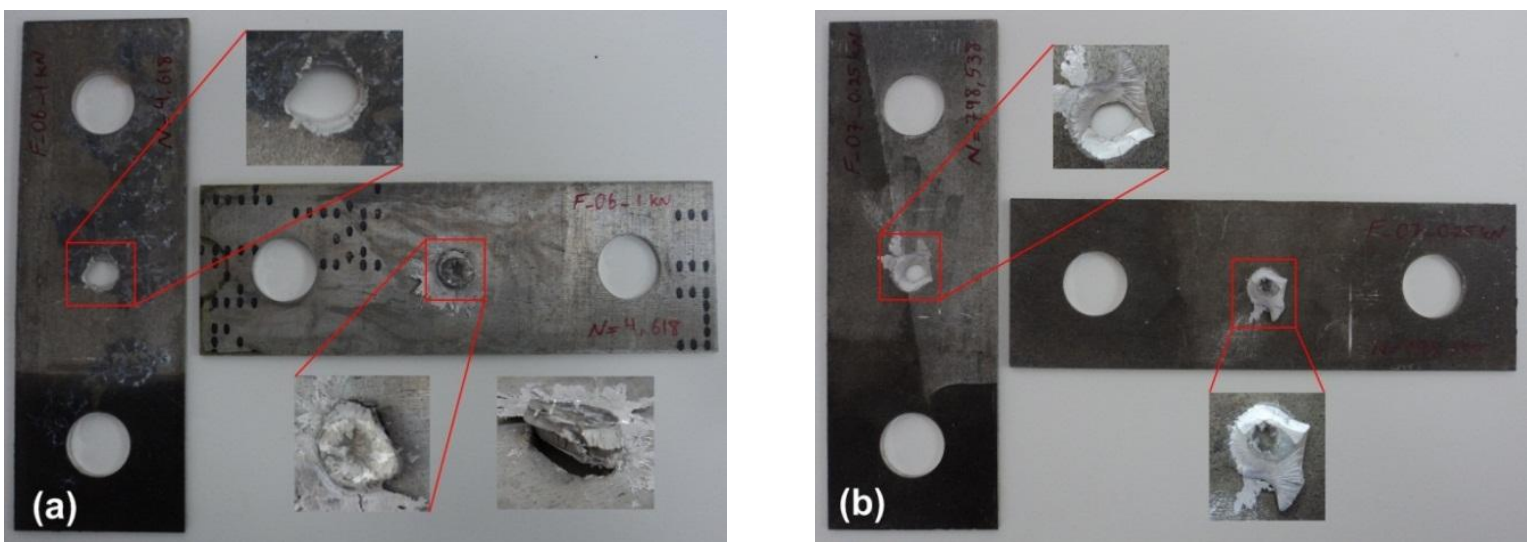

\section{Crack initiation}

Fatigue crack initiation is a progressive phenomenon during which slip deformation happens within several grains under cyclic loading reversals. As they are the weakest, surface grains are more prone to slip plastic deformation. The slip deformation which happens in a cyclic loading reversal is not recovered when loading is reversed; rather, reverse slip occurs in adjacent planes [33]. As a result, fatigue loading forms extrusion/intrusion pairs at the metal surface. Slip plane intrusions are stress concentration sites from where surface fatigue cracks may initiate [34].

Practically, there is no unique definition for fatigue crack initiation. This inconsistency is more evident for welded specimens/structures, especially RSW in which the crack initiation location is not visible. Crack initiation in some studies is assumed when the crack reaches the length of $0.25 \mathrm{~mm}[35,36]$ or $18 \%$ 
of the sheet thickness [17]. Crack initiation is related to compliance in some other research [37, 38]. Fatigue crack initiation in the current research was considered as a 5\% increase in non-dimensional compliance as proposed by the Ford motor company. The compliance, $C$, was defined [39] as

$$
C=E \delta_{a} t / P_{a}
$$

where $E$ is elastic modulus, $t$ is sheet thickness, $\delta_{a}$ is displacement amplitude, and $P_{a}$ is load amplitude. Therefore, to obtain the crack initiation life for a specimen, compliance should be calculated for the entire test and plotted versus loading cycles. Figure 9 schematically represents the compliance curve and how the fatigue crack initiation life is measured.

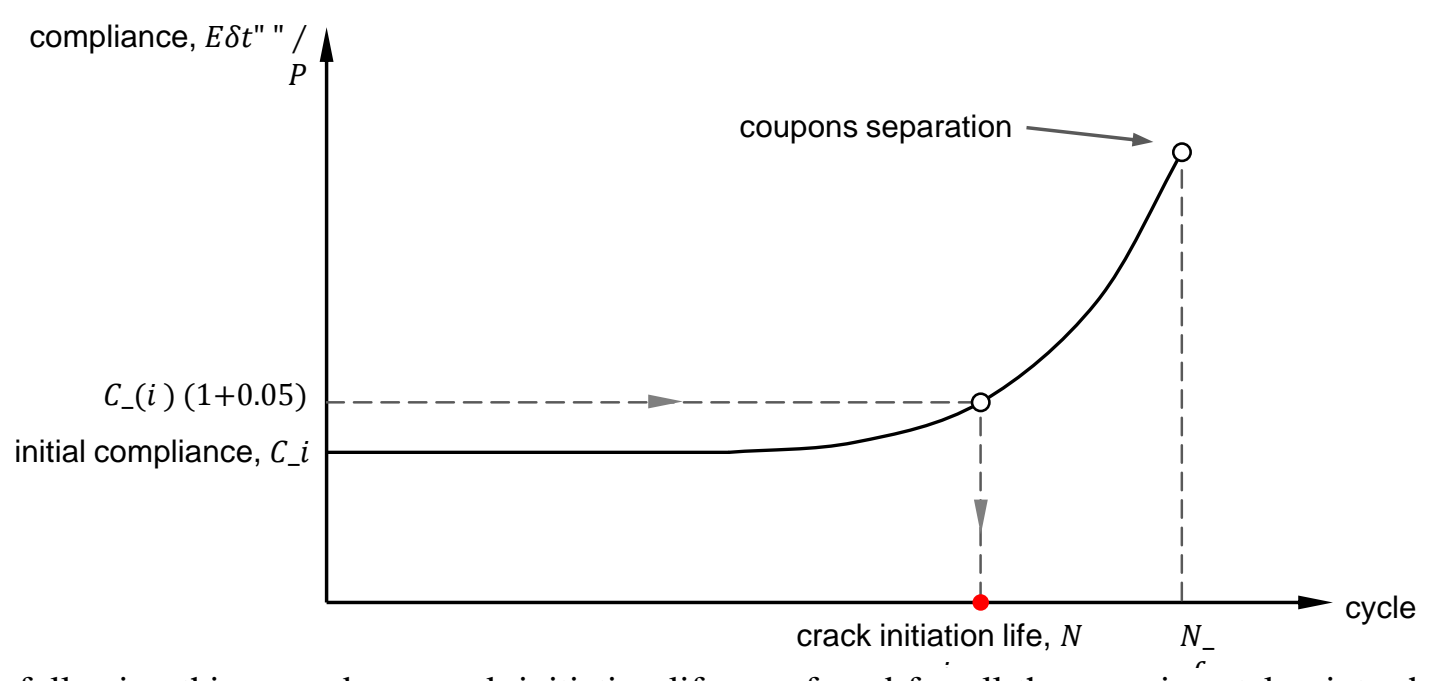

By following this procedure, crack initiation life was found for all the experimental points shown in Figure 5. The results for crack initiation life were normalized by the total life to demonstrate the contribution of crack initiation over different ranges of the fatigue life. Figure 10 illustrates the results for various RSW specimen sets. 


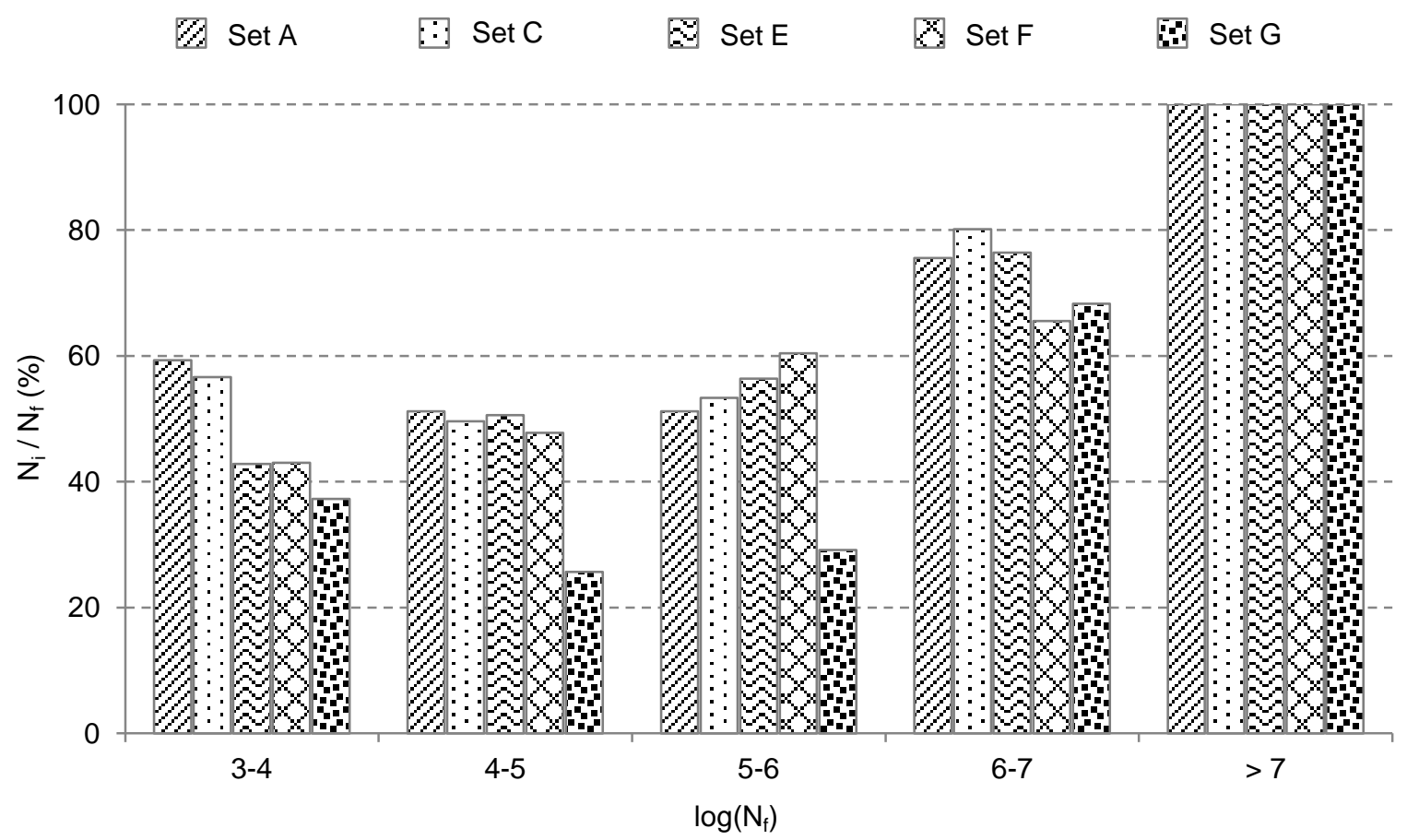

This graph shows that for $N_{f}<10^{6}$ cycles, crack initiation life for magnesium spot-welds in TS configuration (sets A to F) and CT configuration (set G) was around $50 \%$ and $30 \%$ of the total life, respectively. This fraction increased at higher lives such that for run-out tests, i.e., $N_{f}>10^{7}$ cycles, the crack initiation life was equal to the total interrupted life.

\section{Fatigue Modeling}

\subsection{Fatigue modeling theories}

Numerous models have been developed for predicting the fatigue life of spot-welds. These models can be categorized into three major groups: fracture mechanics, structural stress, and local strain approaches. An introduction to these approaches is given in the following sections, and a well-known fatigue model from each approach is explained.

\subsubsection{Fracture Mechanics Approach - Swellam's Model}


In the past four decades, several researchers have considered the spot-weld as a crack-like slit based on some experimental observations and simplifications. The RSW process produces a circular joint between two or more sheets with a notch at the spot-weld edge. Figure 11 displays the edge notch in a magnesium spot-weld. Because the notch radius is small compared to the sheet dimensions, the spot-weld in some studies is considered a sharp notch. Therefore, the spot-weld is treated as a circular region surrounded by a pre-existing crack.

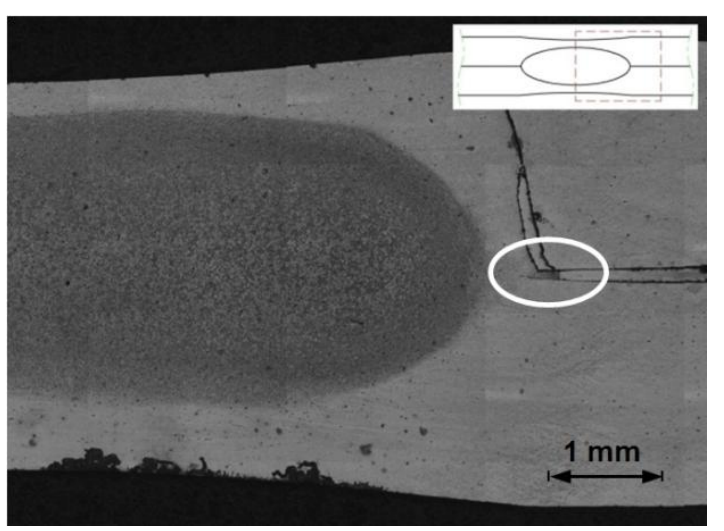

Fatigue failure, in general, consists of fatigue crack initiation and crack propagation processes. For the case of smooth specimens and blunt notched components, where the crack initiation process dominates, fatigue life is closely related to the material strength [40]. However, fatigue life in sharp notched and cracked components is controlled by crack propagation and is insensitive to material strength [41]. Experimental results for steel spot-welds demonstrate that the base metal strength has an insignificant effect on the fatigue life [26, 40]. These observations support the idea that spot-welds are crack-like flaws, and fracture mechanics is the appropriate approach for fatigue modeling.

The fracture mechanics approach considers a measure of stress intensity factor (SIF) or J-integral as the fatigue damage parameter, and relates this parameter to the fatigue life or the crack growth rate.

The fracture mechanics approach has a number of advantages and drawbacks. The main advantage of this approach is that the crack propagation process may be closely followed. A drawback of this approach is that the nugget edge is considered as a crack and therefore crack initiation life is assumed insignificant, 
which is not supported by experimental observations and analysis. The work by Swellam et al. [17] showed that crack initiation life in spot-welds of a low carbon steel overwhelms the crack propagation life in the high cycle fatigue regime, i.e., $N_{f}>10^{5}$ cycles. McMahon et al. [35] demonstrated that up to 55\% of the total fatigue life of spot-welds can be consumed by crack initiation. This ratio in the work by Sheppard et al. [36] is $30 \%$. Another deficiency associated with the fracture mechanics approach is that the formulations are based on the assumption that the crack is along the faying surface; however, it has been shown that through-thickness cracking is more common for TS specimens [16, 26, 27, 31]. Moreover, the SIF formulations are mostly dependent to loading/specimen configurations; therefore, they are not applicable to structures under complex loading.

Swellam et al. in 1992 [17] proposed a fatigue model for predicting crack propagation life for spotwelds based on the fracture mechanics approach. In this model, the effects of modes I and II loading were taken into account. The spot-weld was considered under a general applied load, F, as shown in Figure 12.

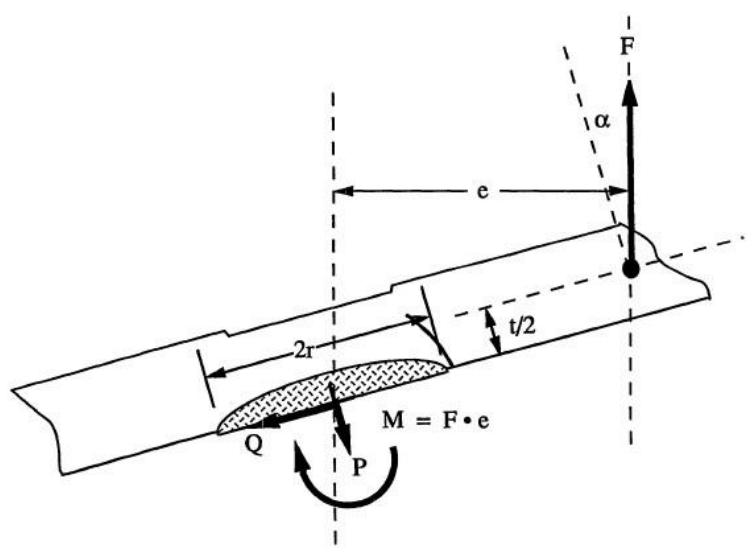

Resultant forces and moments, including axial load, $P$, shear load, $Q$, and bending moment, $M$, at the spot-weld center, were found from static equilibrium of a coupon. The stress intensity factors for two half spaces joined by a circular region were used in this study,

$$
\begin{gathered}
K_{I}=K_{\text {axial }}+K_{\text {moment }}=\frac{P}{2 r \sqrt{\pi r}}+\frac{3 M}{2 r^{2} \sqrt{\pi r}}, \\
K_{I I}=K_{\text {shear }}=\frac{Q}{2 r \sqrt{\pi r}} \quad,
\end{gathered}
$$

where $r$ is the nugget radius. The equivalent mode I SIF, $K_{e q}$, was defined as

$$
K_{e q}=\sqrt{K_{I}^{2}+\beta K_{I I}^{2}}
$$


in which $\beta$ is an empirical material constant, which reflects the material's sensitivity to mode II loading. Experimental results from two or more different spot-weld specimen configurations are required to obtain $\beta$. Some of the specimen sets must involve only the mode I SIF (such as cross-tension or coachpeel configurations), and some other specimens must reflect only the effect of mode II or a combination of modes I and II SIFs. The parameter $\beta$ is found such that the best correlation is achieved for equivalent stress intensities, $K_{e q}$, when plotted versus the fatigue life for all specimen configurations.

A geometrical correction factor, $G$, was defined to incorporate the effects of specimen and nugget size

$$
G=\sqrt{\frac{t^{2} W}{r^{3}}\left(\frac{9 t^{2}}{4 r^{2}}+1\right)},
$$

where $t$ is the sheet thickness, and $W$ is the specimen width. To account for geometrical factors and load ratio, $R$, the general stress intensity parameter, $K_{i}$, was defined as

$$
K_{i}=\frac{K_{e q}}{G} \sqrt{1-R}
$$

and considered as a damage parameter. The SIFs and the damage parameter were assumed constant, i.e., independent of the crack length during the course of cyclic loading. Therefore, fatigue life was obtained from

$$
N=A_{S}\left(K_{i}\right)^{-b_{S}}
$$

where $A_{S}$ and $b_{S}$ are material constants for Swellam's model. These coefficients are obtained by fitting a linear trend line to $\log \left(K_{i}\right)-\log (N)$ curve,

$$
\log \left(K_{i}\right)=-\frac{1}{b_{S}} \log (N)+\frac{\log \left(A_{S}\right)}{b_{S}}
$$

Therefore, the constants are determined by knowing the slope and intercept of the trend line,

$$
b_{S}=-\frac{1}{\text { slope }} \quad ; \quad A_{S}=10^{-\frac{\text { intercept }}{\text { slope }}}
$$

Swellam's model was evaluated in this study by predicting the fatigue life for magnesium spot-welds in TS and CT configurations. Taking advantage of the simple specimen geometry, resultant loads at the 
spot-weld center were determined from hand calculations; hence, no finite element (FE) modeling was required for damage parameter calculation.

\subsubsection{Structural Stress Approach - Sheppard's Model}

Since 1989, a number of fatigue models have been developed for spot-welds based on the structural stress concept. Structural stress is a linearly distributed stress over the thickness, obtained by neglecting the effect of stress concentration. Structural stress reflects the effects of forces and moments at the spotweld center or edge. Structural stress is usually calculated by superposing the effects of different forces and moments, obtained from linear elastic FE simulations. To suit this approach, the sheets and spotwelds in the FE model are represented by shell and beam elements, respectively. The structural stress approach, as opposed to many fracture mechanics-based models, often provides enough flexibility to be applicable to different specimens and structures. Therefore, these models are widely employed in industry, including the automobile industry [42]. However, some weak points are also associated with this approach. A serious shortcoming is that the notch effect at the spot-weld edge is ignored [42].

Sheppard et al. in 2000 [43] developed a fatigue model for spot-welds based on the structural stress concept and assuming through-thickness cracking. Structural stress in this work was a function of membrane load, bending moment, and axial force,

$$
\Delta S_{i j}=\frac{\Delta P_{i j}}{\omega t_{i}}+6 \frac{\Delta \widehat{M}_{i j}^{*}}{t_{i}^{2} W}+1.2 \frac{\Delta P_{A i}}{t_{i}^{2}} \quad ; \quad i, j=1,2
$$

where $\Delta S_{i j}$ is the structural stress range. $\Delta P_{i j}$ and $\Delta P_{A i}$ are membrane load and axial force ranges, respectively. $\omega$ is the effective coupon width and according to Wang et al. [44] was defined as $\pi d / 3$. The subscript $i$ represents the sheet ( $i=1$ for the bottom sheet, and $i=2$ for the top sheet), and the subscript $j$ represents the side $\left(j=1\right.$ for the right side, and $j=2$ for the left side). The bending moment, $\widehat{M}^{*}$, was defined as

$$
\widehat{M}_{i j}^{*}=M_{i j}-M_{a v g}
$$


where $M_{i j}$ is the summation of positive moments on the sheet $i$ and the side $j$, and $M_{\text {avg }}$ is the average of all positive nodal moments at elements adjacent to the spot-weld. The moments causing tension at the interface are considered as positive moments. Figure 13 illustrates the forces and bending moments at the edges of a spot-weld.

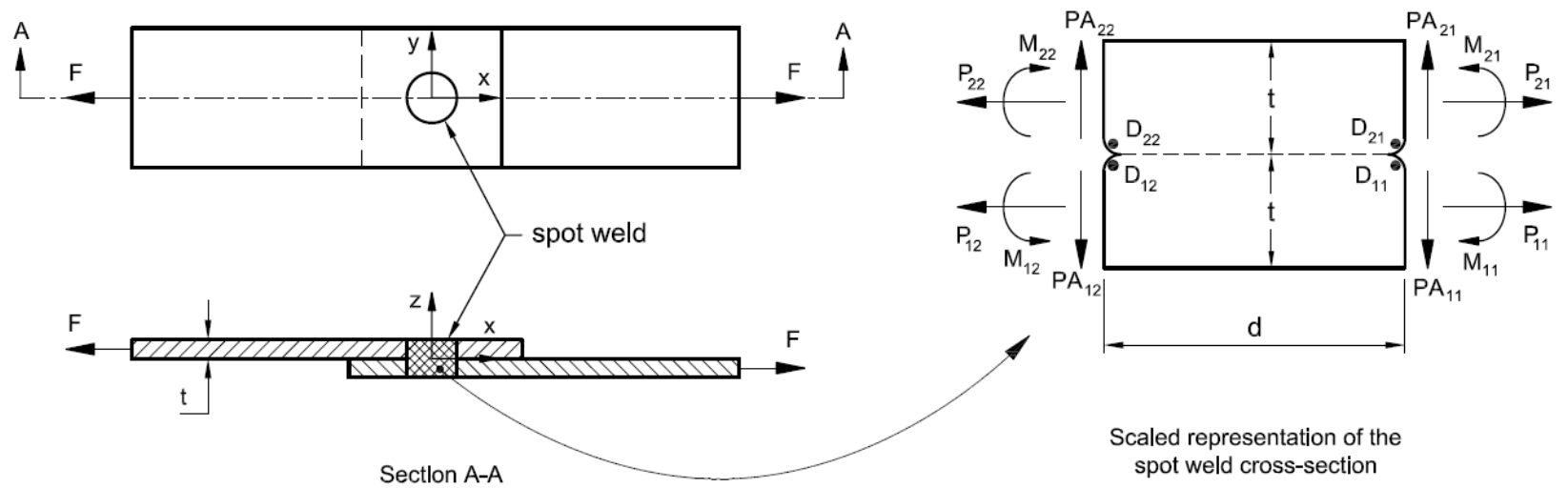

Forces and moments were determined from linear elastic FE simulations. The sheets were represented with four-node linear shell elements, and the spot-weld was modeled with a two-node linear beam element. Material properties for AZ31B-H24 magnesium alloy was linear elastic ( $E=43 \mathrm{GPa}$ and $v=0.35$ ); hence, any strain hardening and asymmetric hardening behavior was suppressed. Nonlinear geometry was included for a correct failure location prediction [45]. The FE models and boundary conditions for tensileshear and cross-tension specimens are illustrated in Figure 14.

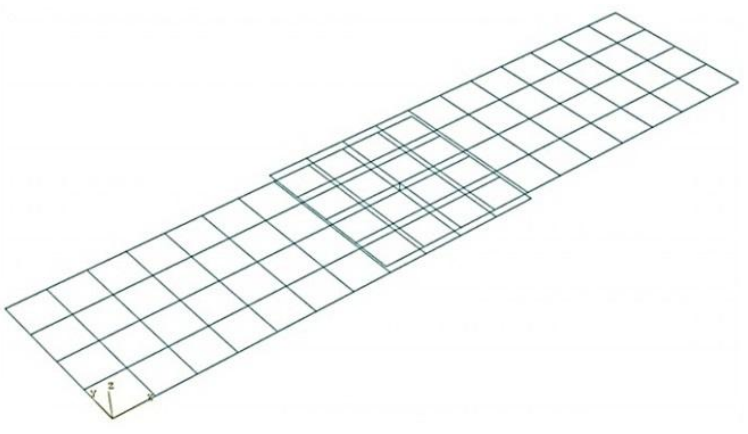

(a)

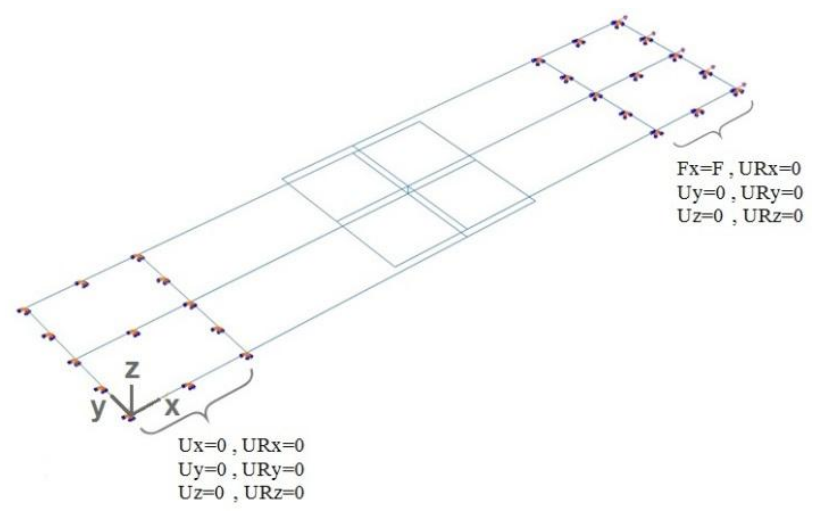




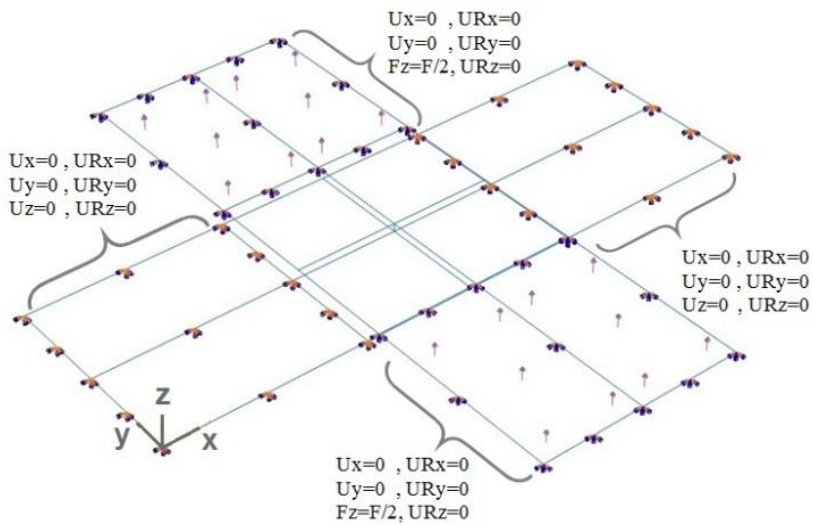

The results for forces and moments are stored in nodal force (NFORC) output variables in Abaqus 6.10 software. One should note that the default setting for averaging element output at nodes has to be deactivated, so that the contribution of each element is represented correctly.

According to equation (10), four values were obtained for the structural stress range at each spot-weld. Maximum structural stress range,

$$
\Delta S_{\max }=\max \left(\Delta S_{11}, \Delta S_{12}, \Delta S_{21}, \Delta S_{22}\right)
$$

were found for SIF and life calculations. Initial and final crack sizes were assumed to be $a_{i}=0.25 \mathrm{~mm}$ and $a_{f}=t$, respectively. Therefore, the relationship to find crack propagation life through Paris' equation was simplified to

$$
N_{p}=\int_{a_{i}}^{a_{f}} \frac{d a}{C(\Delta K)^{m}}=A_{S h}\left(\Delta S_{\max }\right)^{-b_{S h}}
$$

where $N_{p}$ is crack propagation life. $A_{S h}$ and $m_{S h}$ are material constants for Sheppard's model which are determined following the same procedure explained for Swellam's model.

\subsubsection{Local Strain Approach - Pan's Model}

Some studies, in contrast to the fracture mechanics approach, consider a spot-weld as a blunt notch with a finite radius. Therefore, a detailed FE model with a fine mesh at the vicinity of the spot-weld is required. A measure of local strain at the spot-weld edge is often assumed to control fatigue failure in this approach. Local stress/strain values are calculated from an elastic-plastic FE simulation, or from an elastic solution along with a variant of Neuber's rule [46]. An advantage of this approach is that the effect of the 
spot-weld notch is considered. Also, cyclic characteristics of materials, e.g., anisotropy and hardening asymmetry, may be accounted for. On the other hand, crack propagation is not considered in local strain models. Moreover, complexities of FE model preparation, as well as intensive FE calculations, restrict the applicability of this approach for real-life problems.

Pan in 2000 [45] showed that Sheppard's model is capable of successfully predicting fatigue life of steel spot-welds, as long as the sheets being welded have the same thickness, but that the model fails for dissimilar thicknesses. To tackle this problem, Pan in 2002 [19] proposed a model based on the local strain approach.

A detailed FE model was employed in this model to obtain a realistic approximation of local stress and strain values at the hot-spot. The FE model included details of the nugget root radius, which was found from experimental observation. The notch radius was obtained by sectioning spot-welds, and measuring the distance between the two sheets in the vicinity of the nugget. The notch radius in Pan's work was $0.076 \mathrm{~mm}$ for steel spot-welds [19]. Measurements in the current work indicated that the average notch radius for magnesium spot-welds was $0.10 \mathrm{~mm}$, Figure 11.

The maximum principal strain range at the hot-spot was used as the fatigue damage parameter. Therefore, fatigue life was predicted using the following equation,

$$
N=A_{P}\left(\Delta \varepsilon_{\max }^{p r}\right)^{-b_{P}}
$$

in which $\Delta \varepsilon_{\max }^{p r}$ is maximum principal strain range and $A_{P}$ and $b_{P}$ are material constants for Pan's model. These constants are found by fitting a linear trend line to $\log \left(\Delta \varepsilon_{\max }^{p r}\right)-\log (N)$ curve. The hot-spot was identified as the location with the maximum local principal strain at the end of the first reversal. Maximum principal strain range, according to Pan [19], is the difference in the principal strain at the end of the loading and unloading reversals.

The FE model for a TS specimen is shown in Figure 15(a). Half of the TS specimen was modeled, taking advantage of a plane of symmetry. Eight-node linear brick elements with reduced integration were used in this model. Elastic properties of magnesium along with the tensile stabilized cyclic stress-strain 
curve were assigned to AZ31B-H24 sheets (symmetric tension-compression behavior is assumed in Abaqus software). The same material properties were assigned to the base metal and the weld area, i.e., HAZ and FZ, due to lack of suitable mechanical properties for the weld region. Moreover, the work by Pan [45] on HSLA steel showed that nonhomogeneous material properties had a minimal effect on principal strain distribution, nor on the hot-spot location. The Mises criterion was employed as the yield function and kinematic hardening was used to represent the Bauschinger effect. Figure 15(b) illustrates the boundary conditions at the two ends, and on the plane of symmetry. All degrees of freedom (DOFs) were fixed in one end, and the other end was only free to move in the x-direction. The z-symmetry condition $(\mathrm{Uz}=0)$ was applied to the plane of symmetry. Half of the load that was applied in the experiments was exerted due to the half model. Simulations were run for three steps to simulate three consecutive reversals, i.e., loading, unloading, and reloading, while considering the effect of nonlinear geometry. The principal strain ranges at the hot-spot were calculated for available experimental loads.

Figure 15(b) displays the FE model for a quarter CT specimen, which used two planes of symmetry. The notch radius, element type, and material properties were the same as the TS specimen model. The boundary conditions on the CT specimens were applied such that the experimental conditions were simulated. All DOFs on one sheet were fixed within the gripping distance, and on the other sheet the translational DOF normal to the sheet was free, and the other DOFs were fixed. A quarter of the experimental load was applied uniformly on the moving end of the specimen. Two different symmetry boundary conditions (x-symmetry, and z-symmetry) were applied to the symmetry planes. Similar to the TS model, three loading steps were run for CT specimens to simulate one cycle. 

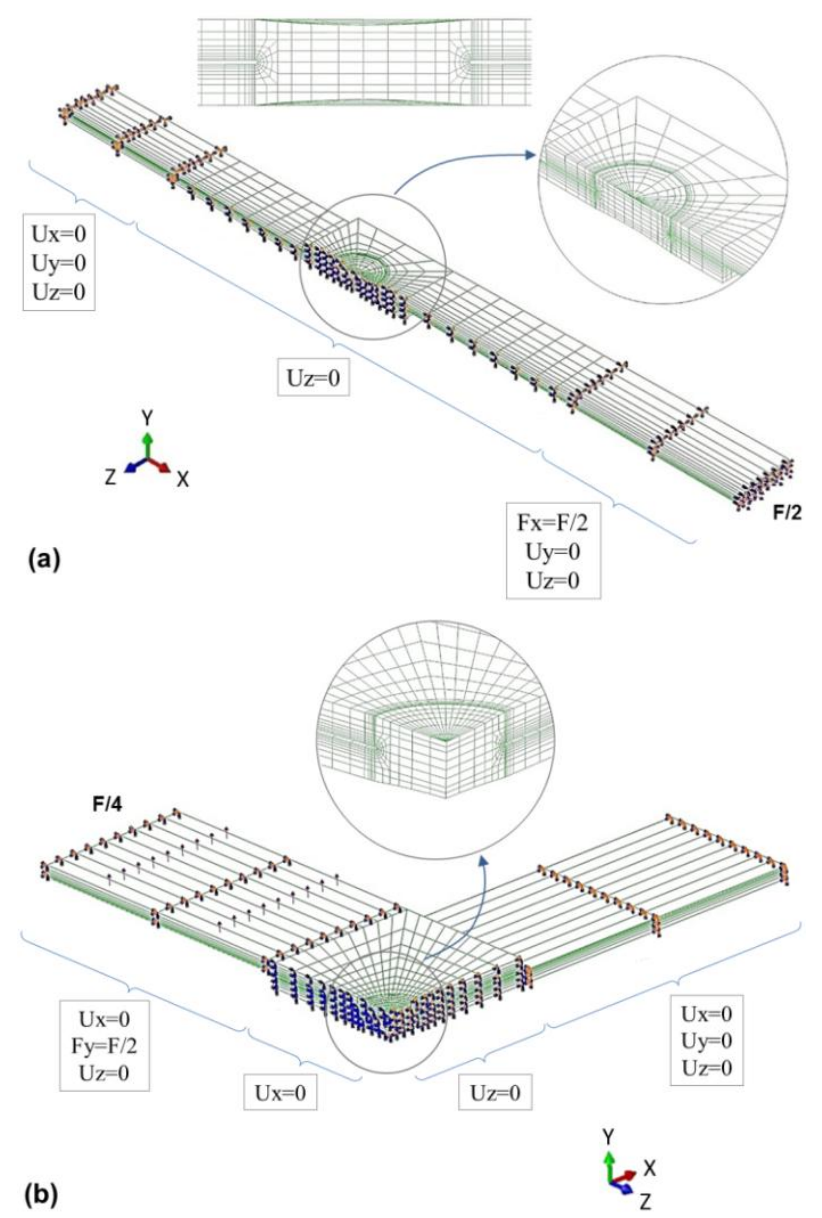

\subsection{Results and discussion}

The fatigue models proposed by Swellam, Sheppard, and Pan were assessed by predicting the fatigue life for magnesium spot-welds. Results are shown and compared in Figure 16.

The damage parameter for Swellam's model was found from equation (6). The graphs in Figure 16(a) illustrate the results for the five specimen sets investigated. Figure 16(a1) displays the data points in terms of the damage parameter along with a bilinear trend line as a result of a sharp bend at a life of $10^{6}$ cycles. As depicted in this figure, data points for CT specimens (Set G) were not appropriately correlated to TS specimens, resulting in a low correlation coefficient of $R^{2}=0.53$. Similarly, Figure 16(a2) shows that while TS data points were mostly located within the factor of 2 bound lines, CT specimen results were left outside the region. The reason for the poor performance is the proposed method for SIF calculation. 
Swellam suggested obtaining SIFs from resultant forces and moments at the center of the spot-weld; therefore, the effect of self-equilibrating forces and moments is ignored in this model. For CT specimens, the resultant bending moment, $M$, and the corresponding SIF, $K_{\text {moment }}$, are zero. Thus, the contribution of bending moment in SIF, which is dominant for CT specimens, is neglected in this model.

For evaluating Sheppard's model, the coefficient for the axial stress term, $\frac{\Delta P_{A i}}{t_{i}^{2}}$, was found for magnesium spot-welds to represent boundary conditions and geometric effects. The coefficient was obtained from the work by Young and Budynas [47]. The values obtained for different sets of spot-welded specimens are listed in Table 4.

Table 4: axial stress coefficient in the Sheppard's model

\begin{tabular}{cccccc}
\hline & Set $\mathbf{A}$ & Set $\mathbf{C}$ & Set $\mathbf{E}$ & Set F & Set G \\
\hline Axial stress coefficient & 1.20 & 1.05 & 0.95 & 1.13 & 1.40 \\
\hline
\end{tabular}

The forces and bending moment at the nugget edge were found through FE simulations. The structural stress range was calculated for all the experimental data points employing equation (10) and using the coefficients presented in Table 4. Figure 16(b) displays the results obtained from Sheppard's model. Figure 16(b1) shows that Sheppard's model was successful in correlating experimental results from different specimen sets, with $R^{2}=0.95$. However, data points corresponding to the CT specimens (set $\mathrm{G}$ ) are slightly shifted from TS specimens. Figure 16(b2) illustrates predicted versus experimental fatigue life utilizing Sheppard's model. This figure shows that almost all experimental data points corresponding to TS specimens (sets A-F) are located within the factor of 2 bound lines, while fatigue life for CT specimens is under-predicted and the points are outside the boundary lines.

Figure 16(c1) displays the maximum principal strain range for Pan's model, obtained from elasticplastic FE simulations. Similar to Swellam's and Sheppard's models, a bilinear trend line was fitted to the data points. This chart indicates that Pan's model was very successful in consolidating the experimental results for different specimen sets, with $R^{2}=0.97$. This figure demonstrates that Pan's model was capable of providing a good correlation between the CT data points (set G) and the TS data points (sets A-F). 
Figure 16(c2) illustrates that almost all experimental data points, including the CT specimens, are located within the factor of 2 boundary lines.

(a) Swellam's model
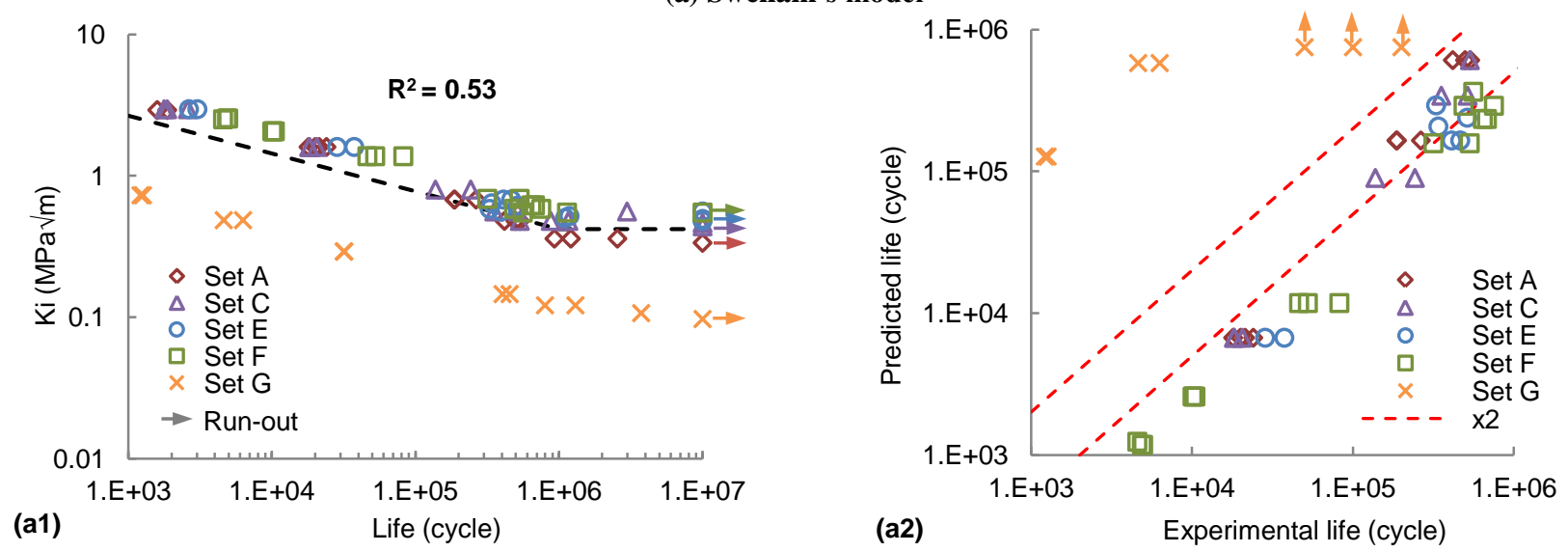

(b) Sheppard's model
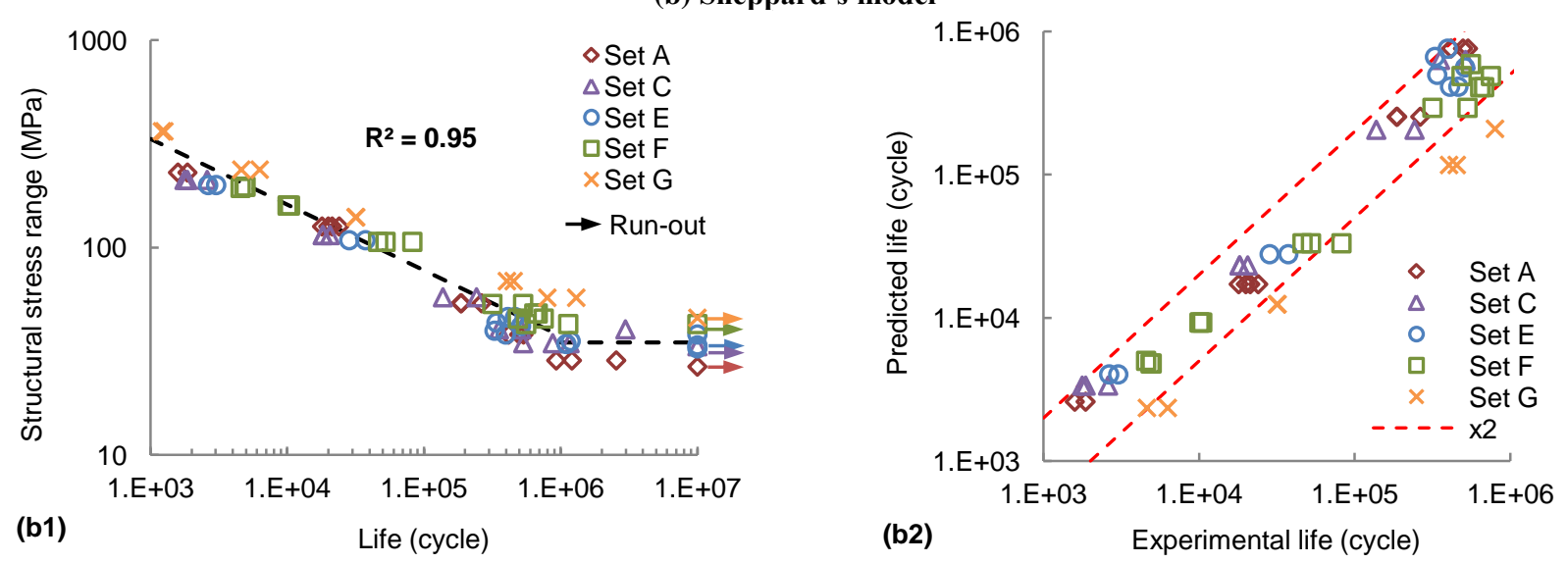

(c) Pan's model
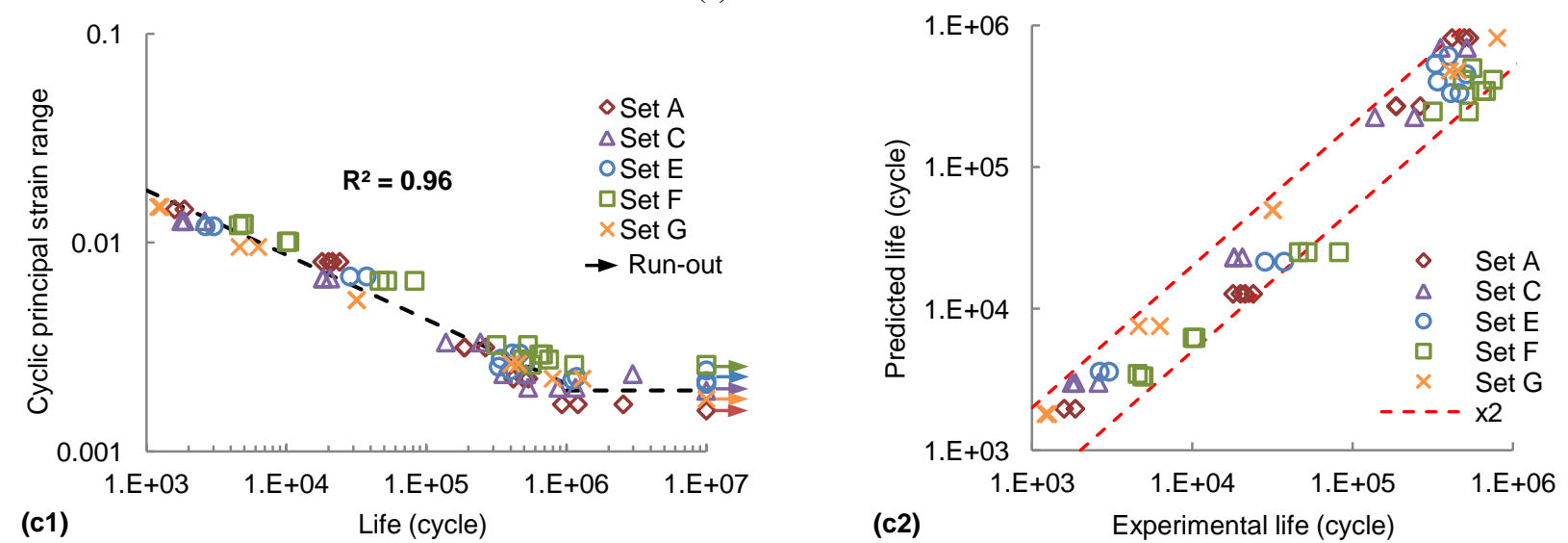

Figure 16(a1) shows that the Swellam's model provides a good correlation between TS specimens in HCF. This is in contrast to what expected as the fracture mechanics approach neglects the crack initiation, 
and Figure 10 illustrates that crack initiation dominates in HCF. On the other hand, Figure 16(c1) demonstrates that Pan's model was successful in LCF, even though crack propagation, which is not appropriately modeled in local approach, dominates in LCF. Nevertheless, one should note that this observation does not justify applicability of fracture mechanics approach in HCF and local approach in LCF. Because fracture mechanics and local approaches only explain the effective damage mechanism in LCF and HCF, respectively.

Figure 16 demonstrates that, although asymmetric hardening behavior of magnesium was neglected by Sheppard's and Pan's model, fatigue life of spot-welds was well predicted. This is likely due to the limited range of experimental data used. The spot-weld configurations investigated in the present research were limited to TS and CT specimens. Moreover, all fatigue tests were performed with a positive R-ratio due to the specific geometry of specimens. Thus, available experimental data do not provide a situation where significant plastic deformations occur at the hot-spot during unloading and reloading reversals. Therefore, the symmetric hardening assumption did not have a significant effect on the stress-strain response and fatigue life prediction. More various configurations of spot-welded specimens and negative R-ratios could make this effect clearer.

\section{Conclusions}

Magnesium spot-welds were characterized in tensile-shear and cross-tension configurations under cyclic loading. Where possible, magnesium spot-weld behavior was compared to that of steel and aluminum spot-welds. The most common fatigue models were assessed and compared for magnesium spot-welds. The following conclusions can be drawn from this study:

1. Fully-reversed fatigue testing of AZ31B-H24 revealed an asymmetric shape of hysteresis loop. This feature was more pronounced at high strain amplitudes.

2. Fatigue strength of magnesium spot-welds is comparable to that of aluminum spot-welds, but is significantly less than steel spot-welds for the similar $d / \sqrt{t}$ ratio. 


\section{Acknowledgements}

This research was performed as a part of the Magnesium Front End Research and Development (MFERD) which is a multi-national project involving universities and companies from Canada, China, and US. The authors would like to acknowledge AUTO21 and NSERC Automotive Partnership Canada for financial support and General Motors for providing AZ31B magnesium sheets. Also, the collaboration of the Material Joining laboratory of the University of Waterloo for providing spot-welded specimens is appreciated.

\section{References}

[1] M.K. Kulekci, Magnesium and Its Alloys Applications in Automotive Industry, International Journal of Advanced Manufacturing Technology, 39 (2008) 851-865.

[2] I. Polmear, Light Alloys: from Traditional Alloys to Nanocrystals, Butterworth-Heinemann, 2006.

[3] Z.B. Sajuri, Y. Miyashita, Y. Hosokai, Y. Mutoh, Effects of Mn Content and Texture on Fatigue Properties of As-Cast and Extruded AZ61 Magnesium Alloys, International Journal of Mechanical Sciences, 48 (2006) 198-209.

[4] M. Matsuzuki, S. Horibe, Analysis of Fatigue Damage Process in Magnesium Alloy AZ31, Materials Science and Engineering: A, 504 (2009) 169-174. 
[5] A. Styczynski, C. Hartig, J. Bohlen, D. Letzig, Cold Rolling Textures in AZ31 Wrought Magnesium Alloy, Scripta Materialia, 50 (2004) 943-947.

[6] A. Chamos, S.G. Pantelakis, G. Haidemenopoulos, E. Kamoutsi, Tensile and Fatigue Behaviour of Wrought Magnesium Alloys AZ31 and AZ61, Fatigue \& Fracture of Engineering Materials \& Structures, 31 (2008) 812-821.

[7] R.W. Rathbun, D.K. Matlock, J.G. Speer, Fatigue Behavior of Spot Welded High-Strength Sheet Steels, Welding Journal, 82 (2003) 207s-218s.

[8] L. Liu, S.Q. Zhou, Y.H. Tian, J.C. Feng, J.P. Jung, Y.N. Zhou, Effects of Surface Conditions on Resistance Spot Welding of Mg Alloy AZ31, Science and Technology of Welding and Joining, 14 (2009) 356-361.

[9] B. Lang, D.Q. Sun, G.Z. Li, X.F. Qin, Effects of Welding Parameters on Microstructure and Mechanical Properties of Resistance Spot Welded Magnesium Alloy Joints, Science and Technology of Welding and Joining, 13 (2008) 698-704.

[10] H. Liu, M.G. Wang, X.Q. Zhang, W. Dong, Effect of Electrode Tip Shape on Strength and Microstructure in Resistance Spot Welding of AZ31B Magnesium Alloy, Advanced Materials Research, 239 (2011) 2528-2532.

[11] J.C. Feng, Y.R. Wang, Z.D. Zhang, Nugget Growth Characteristic for AZ31B Magnesium Alloy during Resistance Spot Welding, Science and Technology of Welding and Joining, 11 (2006) 154-162. [12] W. Xu, D. Chen, L. Liu, H. Mori, Y. Zhou, Microstructure and Mechanical Properties of WeldBonded and Resistance Spot Welded Magnesium-to-Steel Dissimilar Joints, Materials Science and Engineering: A, 537 (2012) 11-24.

[13] V. Patel, S. Bhole, D. Chen, Improving Weld Strength of Magnesium to Aluminium Dissimilar Joints via tin Interlayer During Ultrasonic Spot Welding, Science and Technology of Welding \& Joining, 17 (2012) 342-347.

[14] D. Radaj, Design and Analysis of Fatigue Resistant Welded Structures, Woodhead Publishing Ltd., Abington, Cambridge, 1990.

[15] S.B. Behravesh, L. Liu, H. Jahed, S. Lambert, G. Glinka, Y. Zhou, Effect of Nugget Size on Tensile and Fatigue Strength of Spot Welded AZ31 Magnesium Alloy, in: SAE World Congress \& Exhibition, Detroit, Michigan, United States, 2010.

[16] S.B. Behravesh, H. Jahed, S. Lambert, Characterization of Magnesium Spot Welds under Tensile and Cyclic Loadings, Materials \& Design, 32 (2011) 4890-4900.

[17] M.H. Swellam, P. Kurath, F.V. Lawrence, Electric-Potential-Drop Studies of Fatigue Crack Development in Tensile-Shear Spot Welds, Advances in Fatigue Lifetime Predictive Techniques, 1122 (1992) 383-401.

[18] S.D. Sheppard, Further Refinement of a Methodology for Fatigue Life Estimation in Resistance Spot Weld Connections, in: Advances in Fatigue Lifetime Predictive Techniques: Third Volume, 1996, pp. 265-282.

[19] N. Pan, S. Sheppard, Spot Welds Fatigue Life Prediction With Cyclic Strain Range, International Journal of Fatigue, 24 (2002) 519-528.

[20] ASTM, Standard Practice for Strain-Controlled Fatigue Testing, in, 2004.

[21] AWS, Specification for Resistance Welding for Aerospace Applications, in, 2007.

[22] RWMA, Resistance Welding Manual, 4'th ed., George H Bauchanan, Bridgeport, NJ, USA, 2003.

[23] X. Lou, M. Li, R. Boger, S. Agnew, R. Wagoner, Hardening Evolution of AZ31B Mg Sheet, International Journal of Plasticity, 23 (2007) 44-86.

[24] F. Lv, F. Yang, Q. Duan, Y. Yang, S. Wu, S. Li, Z. Zhang, Fatigue Properties of Rolled Magnesium Alloy (AZ31) Sheet: Influence of Specimen Orientation, International Journal of Fatigue, 33 (2011) 672682.

[25] S.B. Behravesh, Fatigue Characterization and Cyclic Plasticity Modeling of Magnesium Spot Joints, in: Mechanical Engineering, University of Waterloo, 2013.

[26] B. Pollard, Fatigue Strength of Spot Welds in Titanium-Bearing HSLA Steels, in: SAE International Congress and Exposition, Detroit, Michigan, United States, 1982. 
[27] A. Gean, S.A. Westgate, J.C. Kucza, J.C. Ehrstrom, Static and Fatigue Behavior of Spot-welded 5182-0 Aluminum Alloy Sheet, Welding Journal, 78 (1999) 80s-86s.

[28] M. Vural, A. Akkus, B. Eryurek, Effect of Welding Nugget Diameter on the Fatigue Strength of the Resistance Spot Welded Joints of Different Steel Sheets, Journal of Materials Processing Technology, 176 (2006) 127-132.

[29] B.H. Chang, D. Du, B. Sui, Y. Zhou, Z. Wang, F. Heidarzadeh, Effect of Forging Force on Fatigue Behavior of Spot Welded Joints of Aluminum Alloy 5182, Journal of Manufacturing Science and Engineering, 129 (2007) 95-100.

[30] Y. Uematsu, K. Tokaji, Comparison of Fatigue Behaviour Between Resistance Spot and Friction Stir Spot Welded Aluminium Alloy Sheets, Science and Technology of Welding and Joining, 14 (2009) 6271.

[31] X. Long, S.K. Khanna, Fatigue Properties and Failure Characterization of Spot Welded High Strength Steel Sheet, International Journal of Fatigue, 29 (2007) 879-886.

[32] J. Bonnen, H. Agrawal, M. Amaya, R. Iyengar, H. Kang, A. Khosrovaneh, T. Link, M. Shih, M. Walp, B. Yan, Fatigue of Advanced High Strength Steel Spot Welds, in: SAE World Congress \& Exhibition, Detroit, Michigan, United States, 2006.

[33] L.P. Pook, Metal Fatigue: What It Is, Why It Matters, Springer, 2007.

[34] R.I. Stephens, A. Fatemi, R.R. Stephens, H.O. Fuchs, Metal Fatigue in Engineering, Second ed., John Willey \& Sons, New York, 2001.

[35] J.C. McMahon, F.V. Lawrence, Fatigue Crack Initiation and Early Growth in Tensile-Shear Spot Weldments, in, University of Illinois at Urbana-Champaign, 1986.

[36] S.D. Sheppard, M. Strange, Fatigue Life Estimation in Resistance Spot Welds: Initiation and Early Growth Phase, Fatigue \& Fracture of Engineering Materials \& Structures, 15 (1992) 531-549.

[37] F.G. Hamel, J. Masounave, The Fatigue Behaviour of HSLA non-load Carrying Spot Welded Joints, Canadian Metallurgical Quarterly, 29 (1990) 313-318.

[38] H. Lee, N. Kim, T.S. Lee, Overload Failure Curve and Fatigue Behavior of Spot-Welded Specimens, Engineering Fracture Mechanics, 72 (2005) 1203-1221.

[39] Fatigue Testing Procedure for Fusion Welded Coupons, in, Ford Motor Company, 2007.

[40] J.A. Davidson, E.J. Imhof, A Fracture-Mechanics and System-Stiffness Approach to Fatigue Performance of Spot-Welded Sheet Steels, in: SAE International Congress and Exposition, Detroit, Michigan, United States, 1983.

[41] M. Barsom John, T. Rolfe Stanley, Fracture \& Fatigue Control in Structures-Application of Fracture Mechanics, Prentice Hall, New Jersey, 1987.

[42] D. Radaj, C. Sonsino, W. Fricke, Fatigue Assessment of Welded Joints by Local Approaches, Woodhead Publishing Ltd., Cambridge, England, 2006.

[43] S. Sheppard, N. Pan, Z. Bai, Y.C. Sheu, Refinement and Verification of the Structural Stress Method for Fatigue Life Prediction of Resistance Spot Welds Under Variable Amplitude Loads, in: International Body Engineering Conference \& Exposition, Detroit, Michigan, United States, 2000.

[44] P.C. Wang, H.T. Corten, F.V. Lawrence, A Fatigue Life Prediction Method for Tensile-Shear Spot Welds, in: SAE International Congress and Exposition, Detroit, Michigan, United States, 1985.

[45] N. Pan, Fatigue Life Study of Spot Welds, in: Department of Mechanical Engineering, Stanford University, 2000, pp. 178.

[46] H. Neuber, Theory of Stress Concentration for Shear-Strained Prismatical Bodies with Arbitrary Nonlinear Stress-Strain Law, Journal of Applied Mechanics, 28 (1961) 544-550.

[47] W.C. Young, R.G. Budynas, Roark's Formulas for Stress and Strain, McGraw-Hill, New York, 2002. 


\section{Figure Captions}

Figure 1: Specimen geometry for fatigue testing of the base metal

Figure 2: Tensile-shear spot-welded specimen geometries: (a) standard (b) wide (all dimensions are in $\mathrm{mm})$

Figure 3: Cross-tension spot-welded specimen geometry (all dimensions are in inches)

Figure 4: Second and half-life hysteresis loops at different strain amplitudes

Figure 5: Load-life experimental data for spot-welded specimens

Figure 6: Comparison between fatigue performance of magnesium, aluminum [29, 30], and steel [31, 32] spot-welds in TS configuration (d/vt values are in $\mathrm{Vmm})$

Figure 7: Failure modes in TS specimens under cyclic loading (a) interfacial (b) partially-interfacial (c) coupon failure

Figure 8: Fatigue failure modes in CT specimens (a) $\mathrm{P}_{\max }=1 \mathrm{kN}$, life $=4,618$ cycle (b) $\mathrm{P}_{\max }=0.25 \mathrm{kN}$, life $=798,538$ cycle

Figure 9: Illustration of calculating the fatigue crack initiation life

Figure 10: Crack initiation life portion for different RSW specimens

Figure 11: Spot-weld edge notch in a magnesium spot-weld

Figure 12: Resolving a general applied load, F, at the center of the spot-weld [17]

Figure 13: Forces and moments at a spot-weld nugget edge for Sheppard's structural stress calculation [36]

Figure 14: FE model of spot-weld specimens for Sheppard's model (a) TS specimen (b) CT specimen

Figure 15: FE model and boundary conditions for Pan's model (a) a half of TS specimens (b) a quarter of CT specimens

Figure 16: Fatigue models assessment for magnesium spot-welded specimens 